\title{
Outcome Analysis of End-to-End and End-to-Side Anastomoses in 131 Patients Undergoing Microsurgical Free Flap Reconstruction of the Lower Extremity
}

\author{
Sören Könneker, MD ${ }^{1}$ G.F. Broelsch, MD ${ }^{1} \quad$ J.W. Kuhbier, MD ${ }^{1} \quad$ T. Framke, Dipl-Stat ${ }^{2} \quad$ N. Neubert ${ }^{1}$

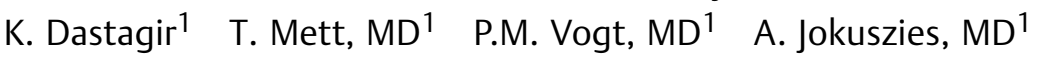 \\ ${ }^{1}$ Department of Plastic, Aesthetic, Hand and Reconstructive Surgery, \\ Hannover Medical School, Hannover, Germany \\ 2 Institute for Biostatistics, Hannover Medical School, Hannover, Germany \\ Address for correspondence Sören Könneker, MD, Department of \\ Plastic, Aesthetic, Hand and Reconstructive Surgery, Hanover Medical \\ School, Carl-Neuberg-Str. 1, 30625 Hanover, Germany \\ (e-mail: koenneker.soeren@mh-hannover.de).
}

J Reconstr Microsurg Open 2017;2:e7-e14.

\begin{abstract}
Background End-to-end and end-to-side anastomoses remain the most common techniques in microsurgical free flap reconstruction. Still, there is an ongoing effort to optimize established techniques and develop novel techniques. Numerous comparative studies have investigated flow dynamics and patency rates of microvascular anastomoses and their impact on flap survival. In contrast, few studies have investigated whether the type of anastomosis influences the outcome of microvascular free flap reconstruction of a lower extremity.

Patients and Methods Retrospectively, we investigated the outcome of 131 consecutive free flaps for lower extremity reconstruction related to the anastomotic technique. Results No statistical significance between arterial or venous anastomoses were found regarding the anastomotic techniques $(p=0.5470)$. However, evaluated separately by vessel type, a trend toward statistical significance for anastomotic technique was observed in the arterial $(p=0.0690)$ and venous $(p=0.1700)$ vessels. No thromboses were found in arterial end-to-end anastomoses and venous end-to-side anastomoses. More venous $(n=18)$ than arterial thromboses $(n=9)$ occurred in primary anastomoses undergoing microsurgical free flap reconstruction $(p=0.0098)$. Flap survival rate

Keywords

- free flap reconstruction

- end-to-end anastomosis

- end-to-side anastomosis was $97.37 \%$ in the end-to-end arterial group versus $86.36 \%$ in the end-to-side group. No thromboses were found in five arterial anastomoses using T-patch technique.

Conclusion For lower extremities, there is a connate higher risk for venous thrombosis in anastomotic regions compared with arterial thrombosis. We observed divergent rates for thromboses between end-to-end and end-to-side anastomoses.

However, if thrombotic events are explained by anastomotic technique and vessel type, the latter carries more importance.
\end{abstract}

The evolution of microsurgery to date has enabled microsurgeons to perform anastomoses of 0.5 -mm-caliber vessels, ${ }^{1}$ so-called "super-microsurgery," and thus facilitating even the most sophisticated free flaps.

received

April 26, 2016 accepted after revision

September 8, 2016

published online

October 27, 2016
In 1997, Samaha et al examined the fate of more than 2,000 microvascular anastomoses in more than 900 tissue transplants, ${ }^{2}$ comparing end-to-end versus end-to-side techniques. In contrast to Godina, who advocated the preferential
Copyright $\odot 2017$ by Thieme Medical Publishers, Inc., 333 Seventh Avenue, New York, NY 10001, USA. Tel: +1(212) 584-4662.
License terms

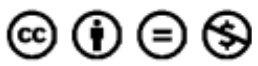

10.1055/s-0036-1593815. ISSN $2377-0813$. 
use of end-to-side arterial anastomoses in lower extremity reconstruction, ${ }^{3}$ Samaha et al could not find any statistical difference between the two techniques. Rather, they proposed to choose the anastomosis technique secondary to factors influencing the choice of recipient vessels as vessel condition, accessibility, and preservation or augmentation of maximal distal flow to an extremity. ${ }^{2,3}$ Tsai et al recommended end-to-side anastomosis when facing vessel-size discrepancy and for preserving the distal circulation of the limb. 4

The aforementioned results were also confirmed by experimental and comparative studies in rats, showing no significant difference in free flap survival for either technique. $^{5-7}$

In cases of difficult clinical situations such as pathologic vessel conditions due to trauma, infection or radiation, vessel wall discrepancy, or deeply located vessels, Verhelle and Heymans suggested T-grafts and a funnel-shaped vein graft. ${ }^{8}$

This retrospective study was performed to demonstrate our experience with end-to-end and end-to-side anastomoses in 131 patients undergoing microvascular lower extremity reconstruction over a period of 6 years.

\section{Patients and Methods}

In this study, we analyzed the outcome of end-to-end and end-to-side anastomoses in all free flaps undergoing reconstructive surgery of the lower extremity. The only exclusion criteria were the missing details about the anastomotic technique in the operation report $(n=1)$. Between 2007 and 2012, 97 male and 34 female patients were treated with 131 flaps in our institution by multiple surgeons. Retrospectively, we analyzed operative reports for anastomotic technique and revision-operative reports for occurrence of thrombotic events. We included only thrombotic events of primary anastomoses in autologous flap transplantation. Overall, we examined the thrombosis rate of 132 arterial and 145 venous primary anastomoses.

Patient age ranged from 7 to 88 years and was 49 years in average. The flaps used for defect closure are summarized in - Fig. 1. The latissimus dorsi flap was the most commonly used flap for lower leg reconstruction (60.31\%).

For evaluation of each individual's vascular status, we obtained peripheral pulses, the ankle brachial index, and arteriography. In case of arteriopathy (i.e., stenosis or interruption) the patients were referred to the radiologist and/or vascular surgeon for interventional improvement of intervention as balloon dilation or bypass surgery.

Selection of recipient vessels was performed in regards to the arteriography findings and defect location. In most cases free flap coverage was performed in supine or lateral decubitus position with end-to-end or end-to-side anastomosis of the anterior or posterior tibial artery. Venous anastomosis was performed on the deep or superficial system according to the intraoperative finding. In case of availability the superficial vein was preferred. All anastomoses were performed hand sutured.

In case of potential pressure on the flap pedicle due to positioning of the patient in the postoperative course, we performed an external fixation.

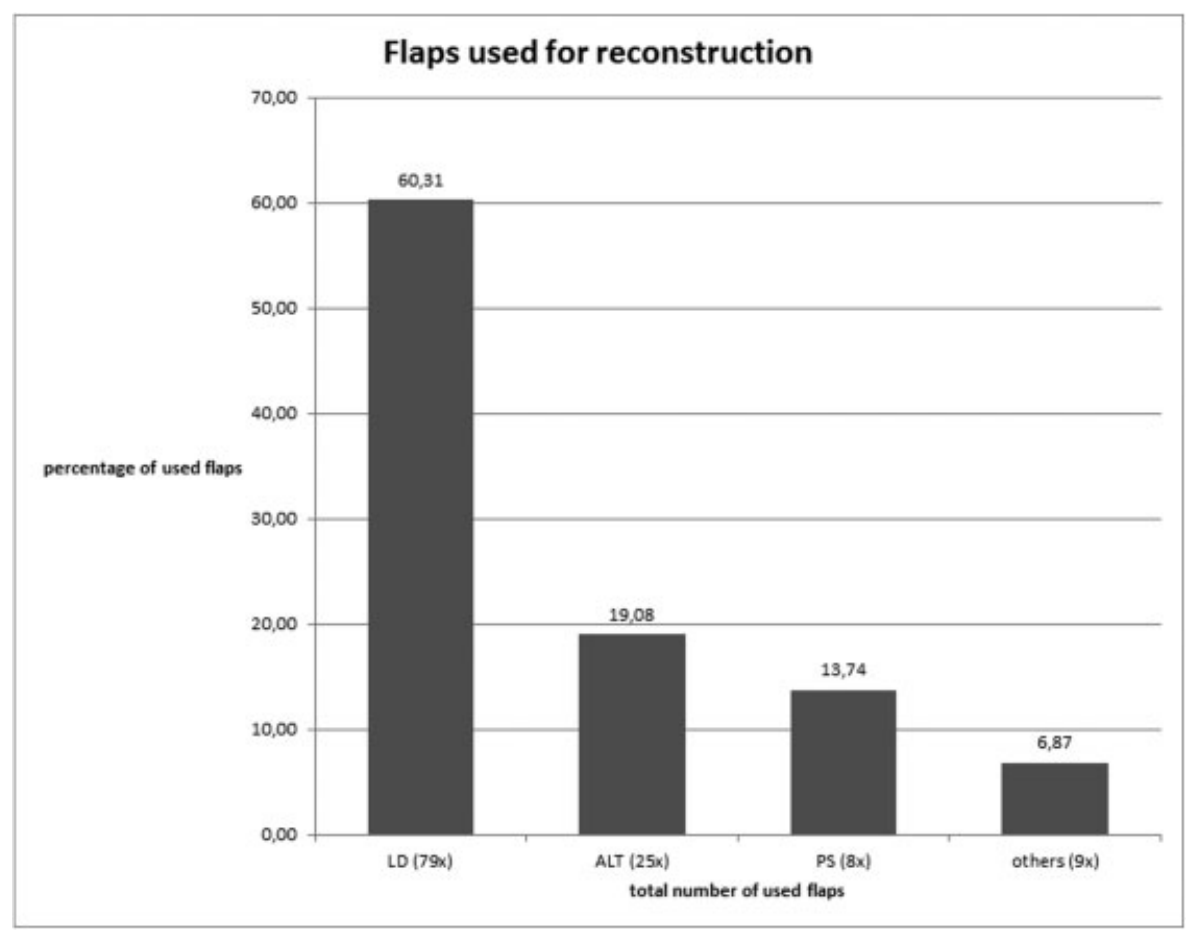

Fig. 1 For reconstruction, 131 flaps were used: Latissimus dorsi (LD) flap was used 79 times, anterolateral thigh (ALT) flap 25 times, parascapular (PS) flap 18 times, and 9 other flaps for covering defects on the lower extremity. On top of the bars, the corresponding percentage of used flaps is shown. 
Table 1 Exact logistic regression model for occurrence of arterial thromboses

\begin{tabular}{|l|l|l|l|l|l|l|}
\hline Variable & Thrombosis & No thrombosis & \multicolumn{2}{l|}{ Model A1 (crude) } & \multicolumn{2}{l|}{ Model A2 (adjusted) } \\
\hline & $\mathrm{N} /$ Total (\%) & $\mathrm{N} /$ Total (\%) & OR (95\% Cl) & $p$ Value & OR (95\% Cl) & $p$ Value \\
\hline Anastomosis & & & & & & \\
\hline End-to-side (Ref.) & $9 / 87(10.3 \%)$ & $78 / 87(89.7 \%)$ & & & & \\
\hline End-to-end & $0 / 42(0 \%)$ & $42 / 42(100 \%)$ & $6.57(1.29, \infty)$ & 0.0501 & $6.060(1.16, \infty)$ & 0.0690 \\
\hline Etiology & & & & & & \\
\hline Trauma (Ref.) & $8 / 99(8.1 \%)$ & $91 / 99(91.9 \%)$ & & & & \\
\hline Infection & $1 / 12(8.3 \%)$ & $11 / 12(91.7 \%)$ & $1.03(0.02,9.09)$ & 1.0000 & $1.14(0.02,11.68)$ & 1.0000 \\
\hline OM & $0 / 3(0 \%)$ & $3 / 3(100 \%)$ & $3.08(0.00,21.60)$ & 1.0000 & $7.18(0.00,136.32)$ & 1.0000 \\
\hline Tumor & $0 / 13(0 \%)$ & $13 / 13(100 \%)$ & $0.66(0.00,3.55)$ & 0.7201 & $0.56(0.00,3.073)$ & 0.6205 \\
\hline Other & $0 / 3(0 \%)$ & $3 / 3(100 \%)$ & $3.08(0.00,21.60)$ & 1.0000 & $5.00(0.00,95.00)$ & 1.0000 \\
\hline Anticoagulation & & & & & & \\
\hline $\begin{array}{l}\text { ASS + heparin } \\
\text { therapeutic dose (Ref.) }\end{array}$ & $0 / 16(0 \%)$ & $16 / 16(100 \%)$ & & & & \\
\hline $\begin{array}{l}\text { ASS + heparin } \\
\text { low-dose prophylactic }\end{array}$ & $5 / 68(7.4 \%)$ & $63 / 68(92.6 \%)$ & $1.65(0.28, \infty)$ & 0.6753 & $1.62(0.26, \infty)$ & 0.6943 \\
\hline Heparin only & $1 / 14(7.1 \%)$ & $13 / 14(92.9 \%)$ & $0.06(0.28, \infty)$ & 0.9333 & $1.80(0.095, \infty)$ & 0.7143 \\
\hline $\begin{array}{l}\text { ASS + heparin } \\
\text { high-dose prophylactic }\end{array}$ & $3 / 32(9.4 \%)$ & $29 / 32(90.6 \%)$ & $0.29(0.28, \infty)$ & 0.5735 & $1.59(0.22, \infty)$ & 0.7187 \\
\hline
\end{tabular}

Abbreviations: ASS, acetylsalicylic acid; Cl, confidence interval; OM, osteomyelitis; OR, odds ratio; Ref., reference group for the regression model. Note: Occurrence of arterial thromboses is presented in columns 2 and 3 with absolute and relative frequencies. All models are from based on exact logistic regression. Model A1 uses thrombosis status (yes/no) as the dependent variable. Anastomosis, etiology, and anticoagulation are included separately as independent variables into the model. Model A2 includes the three independent variables into a single model.

Our anticoagulative protocol consisted of aspirin $100 \mathrm{mg} / \mathrm{d}$ and low-molecular-weight heparin (2,500-5,000 IU body weight adapted) according to the individual thrombotic risk. In case of complicated anastomosis (e.g., atherosclerosis, arterio-venous [AV] loop, major complications with the need for reexploration) or individual risk for thrombosis caused by secondary diagnoses, we performed systemic heparinization (15,000 IU/24 h resp. partial thromboplastin time [PTT] 5060 seconds) during hospital stay.

With respect to their comorbidities and cardiopulmonary performance during the first 24 hours postoperatively, patients were monitored in our intensive care unit (ICU) accordingly. The visible flaps were monitored for clinical signs such as color, capillary refill, congestion, flap turgor, and flap temperature, respectively.

All flaps were monitored hourly during the first 24 hours, every 2 hours throughout the second day, and every 4 hours the following day.

Seroma, hematoma, wound dehiscence, and fat necrosis were considered to be minor complications. Flap compromise due to pressure, kinking, or thrombosis with the need for immediate reexploration was considered to be major complications.

\section{Results}

In this study, 41 of 131 patients underwent a revision operation (31.30\%). Average time of revision was exactly 3 days after flap transplantation. Thrombotic events in the anastomotic region were found and treated in 24 of these patients (18.32\% of all patients; arterial only [ $n=6]$, venous only [ $n=15]$, or both [ $n=3])$. In these cases average time to revision was 1.79 days. The remaining patients $(n=17)$ were treated operatively for other reasons, that is, active bleeding.

We found more venous ( $n=18$ ) than arterial thromboses $(n=9)$ in primary anastomoses undergoing microsurgical free flap reconstruction $(p<0.01)$. No thromboses were found in arterial end-to-end anastomoses and venous endto-side anastomoses, respectively. Nine arterial thromboses were found in arterial end-to-side anastomoses and 18 venous thromboses were found in venous end-to-end anastomoses (-Tables 1, 2). Although there was no statistical significance between the two anastomotic techniques, there was a high trend close to statistical significance for lower thrombotic risk when performing arterial anastomoses in end-to-end technique ( $p=0.0501)$ and a low statistical trend to lower risk when performing venous anastomosis in endto-side technique $(p=0.1818)$.

- Tables 3 and $\mathbf{4}$ summarize the defect characteristics: type of injury, sites of defect, and recipient arterial vessels for supplying the flap. In 99 of 131 cases (75.57\%), trauma injury was causal for lower extremity defects. The tibialis posterior artery was the most commonly used vessel for arterial flap access (61.37\%).

- Tables 5 to $\mathbf{7}$ show the distribution of arterial and venous anastomoses performed. There was one anterolateral thigh 
Table 2 Exact logistic regression model for occurrence of venous thromboses

\begin{tabular}{|l|l|l|l|l|l|l|}
\hline Variable & Thrombosis & No thrombosis & \multicolumn{2}{l|}{ Model V1 (crude) } & \multicolumn{2}{l|}{ Model V2 (adjusted) } \\
\hline & $\mathrm{N} /$ Total (\%) & $\mathrm{N} /$ Total (\%) & OR (95\% Cl) & $p$ Value & OR (95\% Cl) & $p$ Value \\
\hline Anastomosis & & & & & & \\
\hline End-to-side (Ref.) & $0 / 15(0 \%)$ & $15 / 15(100 \%)$ & & & & \\
\hline End-to-end & $18 / 114(15.8 \%)$ & $96 / 114(84.2 \%)$ & $0.26(0.00,1.30)$ & 0.1818 & $0.25(0.00,1.26)$ & 0.1700 \\
\hline Etiology & & & & & & \\
\hline Trauma (Ref.) & $15 / 99(15.2 \%)$ & $84 / 99(84.8 \%)$ & & & & \\
\hline Infection & $2 / 13(15.4 \%)$ & $11 / 13(84.6 \%)$ & $1.02(0.10,5.42)$ & 1.0000 & $1.06(0.10,5.91)$ & 1.0000 \\
\hline OM & $0 / 2(0 \%)$ & $2 / 2(100 \%)$ & $2.37(0.00,20.30)$ & 1.0000 & $1.99(0.00,17.34)$ & 1.0000 \\
\hline Tumor & $1 / 13(7.7 \%)$ & $12 / 13(92.3 \%)$ & $0.47(0.01,3.64)$ & 0.8259 & $0.50(0.01,4.10)$ & 0.9014 \\
\hline Other & $0 / 3(0.0 \%)$ & $3 / 3(100 \%)$ & $1.50(0.00,10.22)$ & 1.0000 & $1.59(0.0,11.18)$ & 1.0000 \\
\hline Anticoagulation & & & & & & \\
\hline $\begin{array}{c}\text { ASS + heparin } \\
\text { therapeutic dose (Ref.) }\end{array}$ & $0 / 16(0 \%)$ & $16 / 16(100 \%)$ & & & & \\
\hline $\begin{array}{c}\text { ASS + heparin } \\
\text { low-dose prophylactic }\end{array}$ & $5 / 68(7.4 \%)$ & $63 / 68(92.6 \%)$ & $0.47(0.11,2.44)$ & 0.4331 & $0.57(0.12,3.04)$ & 0.6210 \\
\hline $\begin{array}{c}\text { Heparin only } \\
\text { ASS + heparin } \\
\text { high-dose prophylactic }\end{array}$ & $1 / 14(7.1 \%)$ & $13 / 14(92.9 \%)$ & $0.24(0.00,2.91)$ & 0.4189 & $0.24(0.00,2.87)$ & 0.4079 \\
\hline
\end{tabular}

Abbreviations: ASS, Aspirin; $\mathrm{Cl}$, confidence interval; OM, osteomyelitis; OR, odds ratio; Ref., reference group for the regression model.

Note: Occurrence of venous thromboses is presented in columns 2 and 3 with absolute and relative frequencies. All models are from based on exact logistic regression. Model A1 uses thrombosis status (yes/no) as the dependent variable. Anastomosis, etiology, and anticoagulation are included separately as independent variables into the model. Model A2 includes the three independent variables into a single model.

Table 3 Etiology and the according sights of main defect in 131 patients

\begin{tabular}{|l|l|l|l|l|l|l|}
\hline Etiology & Foot & Ankle & Lower leg & Knee & Thigh & Total \\
\hline Tumor & 2 & 2 & 7 & 1 & 1 & 13 \\
\hline Trauma & 21 & 4 & 65 & 4 & 5 & 99 \\
\hline Infection & 6 & 1 & 7 & 2 & 0 & 16 \\
\hline Others & 2 & 1 & 0 & 0 & 0 & 3 \\
\hline Total & 31 & 8 & 79 & 7 & 6 & 131 \\
\hline
\end{tabular}

Table 4 Sights of main defects and the recipient arterial vessels for flap reconstruction

\begin{tabular}{|l|l|l|l|l|l|l|l|}
\hline Defect site & Dorsalis pedis & Tibialis anterior & Tibialis posterior & Popliteal & Femoral & Others & Total \\
\hline Foot & 3 & 13 & 16 & & & & 32 \\
\hline Ankle & & & 8 & & & & 8 \\
\hline Lower leg & & 10 & 56 & 4 & 1 & 8 & 79 \\
\hline Knee & & & & 5 & 1 & 1 & 7 \\
\hline Thigh & & & 1 & 1 & 3 & 1 & 6 \\
\hline Total & 3 & 23 & 81 & 10 & 5 & 10 & 132 \\
\hline
\end{tabular}

Note: There was one ALT flap with two anastomoses: dorsalis pedis and tibialis posterior artery (132 arterial anastomoses in 131 flaps and patients).

(ALT) flap with two arterial anastomoses: dorsalis pedis and tibialis posterior artery. In summary, there were 132 arterial anastomoses in 131 flaps and patients (-Tables 4, 5). In 131 flaps there were 14 flaps with more than one venous anasto- mosis resulting in 145 venous anastomoses at all ( - Table 6 ). End-to-end anastomotic technique was preferred in arterial anastomosis and end-to-side anastomotic technique was preferred in venous anastomosis ( - Table 7 ). 
Table 5 Recipient arteries in 132 arterial anastomoses split in end-to-end, end-to-side, and T-shaped anastomoses

\begin{tabular}{|c|c|c|c|c|c|}
\hline \multicolumn{6}{|c|}{ Recipient arteries in arterial anastomosis } \\
\hline & End-to-end & End-to-side & T-shape & Unknown & Summary \\
\hline Dorsalis pedis artery & 2 & 1 & & & 3 \\
\hline Posterior tibial artery & 13 & 64 & 4 & & 81 \\
\hline Anterior tibial artery & 12 & 10 & & 1 & 23 \\
\hline Popliteal artery & 1 & 8 & 1 & & 10 \\
\hline Femoral artery & 1 & 4 & & & 5 \\
\hline Other & 9 & 1 & & & 10 \\
\hline Summary & 38 & 88 & 5 & 1 & 132 \\
\hline
\end{tabular}

Note: One anastomosis technique was not documented (unknown). In 81 cases tibialis, the posterior artery was the most commonly used vessel for arterial flap access (61.83\% of 131 flaps).

Table 6 Recipient veins in 145 venous anastomoses split in end-to-end and end-to-side

\begin{tabular}{|c|c|c|c|c|}
\hline \multicolumn{5}{|c|}{ Recipient veins in venous anastomosis } \\
\hline & End-to-End & End-to-Side & Unknown & Summary \\
\hline Dorsalis pedis artery VC & 2 & & & 2 \\
\hline Posterior tibial artery VC & 58 & 10 & & 68 \\
\hline Anterior tibial artery VC & 16 & & 1 & 17 \\
\hline Popliteal artery VC & 4 & 5 & & 9 \\
\hline Femoral artery VC & 2 & 1 & & 3 \\
\hline Vena saphena magna & 36 & 1 & & 37 \\
\hline Vena saphena parva & 1 & & & 1 \\
\hline Others & 8 & & & 8 \\
\hline Summary & 127 & 17 & 1 & 145 \\
\hline
\end{tabular}

Abbreviation: VC, vena communicants.

Note: One was unknown. In 68 cases vena communicants of tibialis posterior artery was used for venous flap access (51.91\% of 131 flaps).

Table 7 Performed arterial and venous anastomoses at all

\begin{tabular}{|c|c|c|c|c|c|}
\hline \multicolumn{6}{|c|}{ Anastomoses (total) } \\
\hline & End-to-side & End-to-end & T-patch & Unknown & Total \\
\hline Arterial & 88 & $38^{\mathrm{a}}$ & 5 & 1 & 132 \\
\hline Venous & 17 & $127^{b}$ & 0 & 1 & 145 \\
\hline Total & 105 & 165 & 5 & 2 & 277 \\
\hline
\end{tabular}

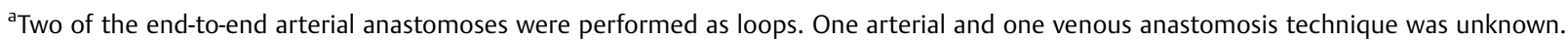

b In 127 venous end-to-end-anastomoses, one Loop and one conduit were used.

\section{Statistical Analysis}

Primary outcome was the occurrence of thrombotic events in arterial and venous anastomoses during inpatient stay. The main question was whether end-to-end or end-to-side techniques are more effective with respect to thrombotic events. Exact logistic regression analyses with thrombotic event as the dependent and surgical technique (end-to-end vs. end-to side), anticoagulation, and etiology as independent variable were performed separately for venous and arterial anasto- moses (models A1 and V1). Subsequently, surgical technique, etiology, and anticoagulation were entered into a multivariable model as the two latter ones are covariables of clinical relevance (models A2 and V2). Two patients were excluded because of two different anastomotic techniques in one vessel type. For statistical analysis, the number of patients, not the number of anastomoses, was counted. Because of the setup of the experiment (thrombotic events are recorded for the arterial und venous anastomoses per patient, and thus are not independent), a generalized estimating equation (GEE) 
model was set up to investigate the effect of location and surgical technique on the occurrence of thrombosis. All odds ratios (ORs) are presented with their corresponding 95\% confidence intervals (CIs). Because of extremely small group sizes and/or groups with no events, the results in the exact logistic regression may not always be reliable and should be viewed with caution.

No adjustments for multiplicity were made due to the exploratory approach of this retrospective trial. The analyses were performed with SAS 9.3 (SAS Institute Inc., Cary, North Carolina, United States).

\section{Results}

In this study, 41 of 131 patients underwent a revision operation (31.30\%). Average time of revision was exactly 3 days after flap transplantation. Thrombotic events in the anastomotic region were found and treated in 24 of these patients (18.32\% of all patients; arterial only [ $n=6]$, venous only [ $n=15]$, or both $[n=3])$. In these cases average time to revision was 1.79 days. The remaining patients $(n=17)$ were treated operatively for other reasons, that is, active bleeding.

We found more venous $(n=18)$ than arterial thromboses $(n=9)$ in primary anastomoses undergoing microsurgical free flap reconstruction $(p<0.01)$. No thromboses were found in arterial end-to-end anastomoses and venous endto-side anastomoses, respectively. Nine arterial thromboses were found in arterial end-to-side anastomoses and 18 venous thromboses were found in venous end-to-end anastomoses (-Tables $\mathbf{1}, \mathbf{2}$ ). Although there was no statistical significance between the two anastomotic techniques, there was a high trend close to statistical significance for lower thrombotic risk when performing arterial anastomoses in end-to-end technique ( $p=0.0501$ ) and a low statistical trend to lower risk when performing venous anastomosis in endto-side technique $(p=0.1818)$.

We found no association between arterial and venous thrombotic events and different etiologies of wounds covered by free flaps $(p=0.72-1.00)$. Eight of nine arterial thromboses were found in trauma etiology and one thrombosis was found in infection etiology. None was found in osteomyelitis (OM) tumor, or other etiologies; 15 venous thromboses were found in trauma etiology, 2 in infection, and 1 in tumor etiology. None was found in OM or other etiologies.

There also was no association between arterial or venous thrombotic events and different patterns of anticoagulation after transplantation of free flaps ( $p=0.42-0.93)$. There was no thrombosis found in acetylsalicylic acid (ASS) plus therapeutic heparin dose group. Low event rates were observed in the remaining groups, which did not yield statistically significant results $(p=0.68, p=0.93$, and $p=0.57)$. We found venous thrombotic events in every anticoagulation group.

In the end-to-end arterial group, flap survival rate after treatment of complications was 97.37 versus $86.36 \%$ in the end-to-side arterial group. Flap survival undergoing T-patch anastomosis technique for arterial anastomoses was $100 \%$ $(n=5)$. Overall flap survival was $90.08 \%$.

All results were separately analyzed for the occurrence of thrombotic events in arterial and venous anastomoses. Because both the arterial and the venous regions are connected to the flap, it cannot be assumed that the events are independent, and thus a GEE model was needed. Thus, a model was set up with thrombotic event (yes/no) as the dependent variable; whereas anastomotic technique (end-to-side/end-to-end) and location (venous/arterial) served as independent variables (-Table 8). Anastomotic technique yielded an OR of 1.19 (reference: end-to-end, 95\% CI: 0.68-2.06, $p=0.5470$ ) and for location an OR of 2.35 (reference: arterial, 95\% CI: $1.23-$ 4.49, $p=0.0096$ ), as shown in - Table 8 .

We assumed that there is an interaction present between the two independent variables; however, we were not able to verify our assumption.

\section{Discussion}

Statistically, we found a trend toward a lower thrombotic risk for venous anastomoses using end-to-side technique although this is the more demanding technique for the microsurgeon. On the other hand, we found a high trend for lower thrombotic risk for arterial anastomoses using end-to-end technique. To decide which technique is used, we based our decision on the availability of recipient vessels and the existence of a one-, two-, or three-vessel-type vascularization of the lower leg. A special note of caution relates to the interpretation of our regression models; extremely

Table 8 GEE model for dependency of anastomotic technique and vessel type on thromboses

\begin{tabular}{|c|c|c|c|c|}
\hline Variable & Thrombosis & No thrombosis & GEE model & \\
\hline & N/Total (\%) & N/Total (\%) & OR $(95 \% \mathrm{Cl})$ & $p$ Value \\
\hline \multicolumn{5}{|c|}{ Anastomosis technique } \\
\hline End-to-side (Ref.) & $9 / 102(8.8 \%)$ & $93 / 102(91.2 \%)$ & & \\
\hline End-to-end & $18 / 156(11.5 \%)$ & $138 / 156(88.5 \%)$ & $1.18(0.683,2.056)$ & 0.5470 \\
\hline \multicolumn{5}{|l|}{ Vessel type } \\
\hline Venous (Ref.) & $18 / 129(14 \%)$ & $111 / 129(86 \%)$ & & \\
\hline Arterial & $9 / 129(7 \%)$ & $120 / 129(93 \%)$ & $2.353(1.232,4.494)$ & 0.0096 \\
\hline
\end{tabular}

Abbreviations: $\mathrm{Cl}$, confidence interval; GEE, generalized estimating equation; OR, odds ratio; Ref., reference group for the regression model. 
unbalanced group sizes and groups with no events impose limitations to this approach.

Cho at al demonstrated no advantages for end-to-end or endto-side technique of arterial anastomoses based on reconstructive outcomes for lower extremity free tissue transfer. ${ }^{9}$ In addition, we found no significant difference in outcome of end-to-end or end-to-side arterial anastomoses. Our trend for lower thrombotic rates of end-to-end arterial anastomoses may be observed because this technique is simpler to perform. ${ }^{2}$

In this study, we found more venous than arterial thromboses in early flap monitoring. Thrombotic events are common in the general population with high incidence rates of 1.43 per 1,000 person-years, deep venous thrombosis of the lower leg being the most common location for thrombosis. ${ }^{10}$ Several risk factors for thrombosis are known, that is, the incidence of deep venous thrombosis in specific patient groups such as in operative medicine reaches up to $80 \%{ }^{11,12}$ Substitution of heparin is the main therapy in inpatient prophylaxis of thrombosis and new oral anticoagulants need to show efficacy. ${ }^{13}$

Nevertheless, thrombotic events are common and major complications in free flap reconstruction of the lower extremity and can lead to flap failure. Fujiki et al observed that venous thromboses are more frequent than arterial thromboses in free flaps to the lower extremities. ${ }^{14}$ They also demonstrated better results for flow-through anastomoses in comparison to end-to-end and end-to-side anastomoses. Miyamoto et al showed advantages in blood flow for flowthrough arterial anastomoses in a mouse model. ${ }^{15}$ In addition, we observed no thrombotic events in five arterial Tpatch anastomoses. However, the possibility for flap removal and access in T-patch technique is not always given.

Optimizing anastomotic techniques is an ongoing process. In microsurgery Chernichenko et al demonstrated the feasibility of end-to-side venous anastomoses using an anastomotic coupling device for microvascular free-tissue transfer in head and neck reconstruction with excellent outcomes. ${ }^{16}$ In contrast, our clinic still adheres to prepare each anastomosis by hand without devices for proceeding individually, training microsurgery and saving costs. However, in our studies all 15 end-to-side venous anastomoses were performed by hand without thrombotic events observed. One possible explanation for this observed lower thrombotic rate is that these end-to-side venous anastomoses get access to the deeper vein system in all cases (-Table 6). These deeper veins may have a better backflow caused by muscle pump function and a common vascular sheath with their accompanying artery. Possible causes of thrombotic complications such as edema, flap compression, and rheologic disturbances might have more influence to the superficial vein system although strictly avoiding these factors is part of our perioperative management.

Using a venous coupler for end-to-end anastomoses could lead to a lower thrombosis rate for this group in our studies, but as a venous coupler device is not established in our clinic, this is therefore a question of debate.

Ahmadi et al showed that performing two venous anastomoses in one free flap can reduce the complication rate. ${ }^{17}$ This observation may have potential also might be a possibility to reduce flap failure but is bounded to the existence of suitable donor veins. However, in our series we found three venous thromboses in 14 patients with two venous anastomoses in the same flap.

For optimal outcome in free flap reconstruction, various influencing factors exist. Individual patient factors, that is, compliance, comorbidities, and vascular status need to be considered. Several groups showed the influence of individual factors, for example vascular status via the ankle brachial index, ${ }^{18}$ or diabetes. ${ }^{19}$ A body mass index greater than $30 \mathrm{~kg} /$ $\mathrm{m}^{2}$ does not seem to increase complication rates ${ }^{20}$ but influences the thickness of different flap-types in a different manner ${ }^{21}$ and has to be considered in preoperative flap choosing anyway. Wettstein et al observed a higher complication rate with increased age of patient. ${ }^{22}$

Optimization of the perioperative management with individually based anticoagulative protocols requires further progress. Real-time monitoring of the hemostasis via thromboelastometry ${ }^{23}$ and intra-arterial thrombolysis in case of thrombotic events ${ }^{24}$ could be additional tools in the future. However, there was no statistical correlation between the thrombosis rates of arterial or venous anastomoses and the extent of anticoagulation. This observation was not surprising because the anticoagulation was adapted individually to the thrombotic risk of each patient.

In our series revision operations were necessary in $31.30 \%$ of all flaps, but after treatment of complications, flap survival rate was $90.08 \%$. These results demonstrate the importance of close flap-monitoring post surgery.

In regards to the aforementioned and various other influencing factors for the outcome of free flap reconstruction, therapy will always be individually based and new aspects and methods will continue to develop in the field of plastic surgery.

\section{Conclusion}

Convincing data suggest that the survival rate of free flaps to the lower extremity depends on factors such as the right choice of suitable recipient vessels, an excellent anastomotic technique by an experienced surgeon, and an optimized perioperative management. For lower extremities there is a connate higher risk for venous thrombosis in anastomotic regions compared with arterial thrombosis. We have observed that rates for thromboses between end-to-end and end-to-side anastomoses present a reverse relation, considered separately by vessel type. However, if thrombotic events are explained by anastomotic technique and vessel type, the latter factor deserves further recognition.

\section{References}

1 Koshima I, Inagawa K, Yamamoto M, Moriguchi T. New microsurgical breast reconstruction using free paraumbilical perforator adiposal flaps. Plast Reconstr Surg 2000;106(1):61-65

2 Samaha FJ, Oliva A, Buncke GM, Buncke HJ, Siko PP. A clinical study of end-to-end versus end-to-side techniques for microvascular anastomosis. Plast Reconstr Surg 1997;99(4): $1109-1111$ 
3 Godina M. Preferential use of end-to-side arterial anastomoses in free flap transfers. Plast Reconstr Surg 1979;64(5):673-682

4 Tsai YT, Lin TS. The suitability of end-to-side microvascular anastomosis in free flap transfer for limb reconstruction. Ann Plast Surg 2012;68(2):171-174

5 Albertengo JB, Rodriguez A, Buncke HJ, Hall EJ. A comparative study of flap survival rates in end-to-end and end-to-side microvascular anastomosis. Plast Reconstr Surg 1981;67(2):194-199

6 Ueda K, Harii K, Nakatsuka T, Asato H, Yamada A. Comparison of end-to-end and end-to-side venous anastomosis in free-tissue transfer following resection of head and neck tumors. Microsurgery 1996;17(3):146-149

7 Frodel JL, Trachy R, Cummings CW. End-to-end and end-to-side microvascular anastomoses: a comparative study. Microsurgery 1986;7(3):117-123

8 Verhelle NA, Heymans $\mathrm{O}$. How to deal with difficult microsurgical end-to-side anastomoses. Microsurgery 2005;25(3):203-208

9 Cho EH, Garcia RM, Blau J, et al. Microvascular anastomoses using end-to-end versus end-to-side technique in lower extremity free tissue transfer. J Reconstr Microsurg 2016;32(2): 114-120

10 Naess IA, Christiansen SC, Romundstad P, Cannegieter SC, Rosendaal FR, Hammerstrøm J. Incidence and mortality of venous thrombosis: a population-based study. J Thromb Haemost 2007; 5(4):692-699

11 Geerts WH, Bergqvist D, Pineo GF, et al; American College of Chest Physicians. Prevention of venous thromboembolism: American College of Chest Physicians Evidence-Based Clinical Practice Guidelines (8th edition). Chest 2008;133(6, Suppl)381S-453S

12 Samama CM, Geerts WH. [Prevention of intraoperative venous thromboembolism: what are the American College of Chest Physicians Evidence-Based Clinical Practice Guidelines (8th edition)?] [in French] Ann Fr Anesth Reanim 2009;28(9, Suppl) S23-S28

13 Mandernach MW, Beyth RJ, Rajasekhar A. Apixaban for the prophylaxis and treatment of deep vein thrombosis and pulmonary embolism: an evidence-based review. Ther Clin Risk Manag 2015;11:1273-1282
14 Fujiki M, Miyamoto S, Sakuraba M. Flow-through anastomosis for both the artery and vein in leg free flap transfer. Microsurgery 2015;35(7):536-540

15 Miyamoto S, Okazaki M, Ohura N, Shiraishi T, Takushima A, Harii K. Comparative study of different combinations of microvascular anastomoses in a rat model: end-to-end, end-to-side, and flowthrough anastomosis. Plast Reconstr Surg 2008;122(2):449-455

16 Chernichenko N, Ross DA, Shin J, Sasaki CT, Ariyan S. End-to-side venous anastomosis with an anastomotic coupling device for microvascular free-tissue transfer in head and neck reconstruction. Laryngoscope 2008;118(12):2146-2150

17 Ahmadi I, Herle P, Rozen WM, Leong J. One versus two venous anastomoses in microsurgical free flaps: a meta-analysis. J Reconstr Microsurg 2014;30(6):413-418

18 McDermott MM, Greenland P, Liu K, et al. The ankle brachial index is associated with leg function and physical activity: the Walking and Leg Circulation Study. Ann Intern Med 2002;136(12):873-883

19 Fischer JP, Wink JD, Nelson JA, et al. A retrospective review of outcomes and flap selection in free tissue transfers for complex lower extremity reconstruction. J Reconstr Microsurg 2013;29(6): 407-416

20 de la Garza G, Militsakh O, Panwar A, et al. Obesity and perioperative complications in head and neck free tissue reconstruction. Head Neck 2016;38(Suppl 1):E1188-E1191

21 Hakim SG, Jacobsen HC, Trenkle T, Sieg P, Wieker H. Impact of body mass index, gender, and smoking on thickness of free soft tissue flaps used for orofacial reconstruction. J Craniomaxillofac Surg 2015;43(8):1325-1329

22 Wettstein R, Schürch R, Banic A, Erni D, Harder Y. Review of 197 consecutive free flap reconstructions in the lower extremity. J Plast Reconstr Aesthet Surg 2008;61(7):772-776

23 Wikner J, Beck-Broichsitter BE, Schlesinger S, et al. Thromboelastometry: a contribution to perioperative free-flap management. J Craniomaxillofac Surg 2015;43(7):1065-1071

24 Senchenkov A, Lemaine V, Tran NV. Management of perioperative microvascular thrombotic complications-the use of multiagent anticoagulation algorithm in 395 consecutive free flaps. J Plast Reconstr Aesthet Surg 2015;68(9):1293-1303 